\title{
Networks and learning: communities, practices and the metaphor of networks
}

\author{
Chris Jones* \\ Lancaster University, UK
}

This article argues that the use of the network metaphor can link together various different aspects of research into the use of advanced learning technologies based on computer networks. The idea of networked learning has become commonplace as an alternative to e-learning that stresses the interaction of learners, tutors and resources through networks. The arguments put in this article are firstly that learning technology needs to take account of the wider debate about networks and secondly that research in this field needs to address the theoretical and practical issues raised by advances in the field of networks. A third point is that the idea of the network acts as a powerful metaphor even if we are able to discount any particular theory generated in its support. The network metaphor can act as a unifying concept allowing us to bring together apparently disparate elements of the field. Networks are an important issue in the study of learning using advanced technologies and they speak to some of the central issues in learning theory such as virtual communities and communities of practice.

\section{Introduction}

The growth of the Internet and specifically the Web has opened up an apparently limitless field for communication and the searching out of resources. However, theoretical approaches to computer networks have hardly kept pace with the spectacular adoption of networks in fields such as education and learning. At the same time we are increasingly aware of the 'small world phenomenon', those strange connections that seem to emerge and make this vast expanse feel much closer and more limited (Watts \& Strogatz, 1998). Castells has recently written about the way in which the possibilities and limits of the Internet play out in relation to community (Castells, 2001). He claims that the Internet is especially effective at maintaining weak ties (p. 129) as well as strong ties at a distance. In education the focus has often been on the latter, with an interest in community and communities of practice being strongly

\footnotetext{
* Centre for Studies in Advanced Learning Technology, Lancaster University, Cartmel College, Lancaster, LA1 4YL, UK. Email: c.r.jones@lancaster.ac.uk
} 
related to the introduction of networked technologies. The 2003 Association for Learning Technology Conference had as its main theme Communities of Practice. The definition offered in the introductory thoughts for delegates noted that, in this approach, learning involved a process of engagement in a community of practice and that the distinctive feature of a community of practice was sharing practice. Shared practice in turn requires members to have the time and space to collaborate (Lave \& Wenger, 1991; Wenger, 1998). By contrast, Castells suggests that the pattern of the Internet is one of 'networked individualism'. Castells also makes the point that on-line communities may emerge but that they rely on networks built out of an interaction between off-line and on-line sociability. This stress on the interconnection between off-line and on-line elements is a corrective to the often-overhyped claims for Virtual Universities and the notion that online worlds are somehow sequestered from real life concerns and processes.

\section{Networks}

Networks are providing an interdisciplinary framework for understanding a wide range of phenomena. The use of the term is not neutral and John Law has noted that the ubiquitous nature of the metaphor may be due to more than the emergence of new social forms. Indeed, it is possible:

that we are in the process of uncritically reproducing some kind of dominant ideology. We are reproducing the ways in which the current orderings of the world like to represent themselves. (Law, draft: para 1)

As such, networked learning is part of a hegemonic discourse not simply in educational terms but as part of wider debates concerning the nature of social processes, power and culture. Law notes that when we analyse in terms of networks, we also help to perform networks into being. The danger he identifies is that when we write as network analysts we may be buying into and adding strength to a managerialist agenda. I give this point prominence here as a corrective to any suggestion that might arise in what follows that networks can be adopted uncritically as a technical term solving a number of practical problems. Networks have within them a latent politics that must be considered in our work.

At a simple level, mathematical modelling of networks concerns itself with the description of phenomena in terms of nodes and the links between them. Basic techniques focus on the ways in which transfers can take place across a network, for example whether the network is traversable or not. The importance of this field of study is that it holds out the prospect of developing mathematical laws of networks that may prove to be robust in describing a broad range of phenomena. In recent years a number of texts aimed at lay readers, originating in mathematical and physical science traditions, have begun to examine phenomena from a wide range of areas, including social and biological domains (Barabasi, 2002; Buchanan, 2002). Network analysis examines systems through the links between nodes in a web-like structure. The nodes can be Web documents, individuals, groups, publications or language. 
Within this paper I make no proper assessment of these broad claims; rather my intention is to draw attention to the literature, its relevance to the field of networked learning and a number of conceptualisations that arise from this work.

Work reported by Barabasi has argued that advances in the characterisation of complex networks that focus on scale-free and hierarchical architectures demonstrate that a wide range of complex networks, including the Web and Internet, share these properties (2002). Without attempting to develop the maths involved in a proper description of scale-free networks, it is important to state that these networks differ from random networks in which nodes are connected without any organising principle. Scale-free networks show a degree of organisation; in particular they display a power-law distribution. Those nodes with only a few links are numerous, but a few nodes have a very large number of links. The power law distribution is radically different from the familiar bell curve distribution with the distribution tapering off towards both margins. The rationale behind this kind of distribution rests on some simple propositions. Firstly networks grow through the addition of new nodes and these new nodes link to pre-existing nodes. Secondly there are preferential attachments within the network such that the probability of linking to a pre-existing node is higher if that node already has a large number of attachments.

As well as being scale-free, most networks also display a high degree of clustering. This clustering is consistent with the predictions of scale-free descriptions of networks with a power law distribution, if a hierarchical organisation is introduced into the network model. The presence of the hierarchical structure helps to re-interpret the role of hubs in complex networks. The theory predicts a modular topology with self-nesting groups of nodes in clusters with dense interconnections. The overall suggestion is that networks are:

... far from random, but they evolve following robust self-organising principles and evolutionary laws that cross discipline boundaries. (Barabasi et al., 2002)

The interesting nature of these networks retains some of the advantages of random networks (such as few steps between any two nodes) with the features of organisation.

Mark Buchanan (2002) concentrates on recent developments in a well-known set of mathematical problems known as 'small world phenomena'. The most popularised form of this problem is in the idea of 'six-degrees of separation': that any one person is likely to be connected to any other through only six steps. One of the key elements in the description of the networking structures and patterns that lie behind smallworld phenomena is the idea of the strength of weak ties. Strong links, for example between close family members, do not reach out very far. It is often the weaker links that can bridge between quite different clusters in networked worlds. Buchanan reports a light-hearted challenge in a German newspaper to connect a Turkish kebabshop owner in Frankfurt with his favourite actor, Marlon Brando. This was done using no more than six links of personal acquaintance using a bridging weak link, a friend of the kebab-shop owner living in California. The small world phenomenon draws attention to the need for weak links and bridging contacts to the organisation of networks. These links are central to the dissemination and propagation of ideas and 
are of particular interest in education. Together the idea of networks as having a selfnested topology and the idea of small worlds begins to map networks as self-organising structures that lie somewhere between order and chaos. This positioning of networks on the border of order and chaos offers a tantalising link with theories that have suggested chaos and complexity theory as potentially rich sources of ideas for analysing education (e.g. Barnett, 2000).

\section{Network society}

Networks and the development of the Internet have profoundly affected our views about how computers have impacted social life, education and learning. Social theories that postulated a new form of society in which industry and factory production were replaced by service industry pre-dated the development of networks by some years. This point is worth noting, as theories of the 'information' society, developed well before networked computing, are often presented as outcomes of the application of computer technology. Daniel Bell's idea that just as industrial society had replaced agrarian society so a new post-industrial society based on services would replace industrial society (1974) was later popularised in Alvin Toffler's writings as The Third Wave (1980). Steve Wosniak, one of the originators of the personal computer at Apple has been quoted as saying that the inventors of the PC were self-consciously exploring the idea of a technological revolution reshaping society (Lyon, 1995). Whilst the PC was an invention tangential to the development of networks, this comment implies a much more sophisticated relationship between technology and society than simple technological determinism-one in which the design of technical artefacts was informed by the very debates that claim technology as their source.

The information society debate still influences discussions of how networks affect education and society. Policy is often based upon the idea of computer networks being the prime lever for social change; for example a recent Minister of Education in the UK remarked:

\footnotetext{
When you look back at the development of our schools it has been very strangely evolutionary. One of the reasons for that is there has not been a development, there has not been an invention which has brought about a transformation which has signalled the revolution and if you look at health it was maybe antibiotics or it was maybe the discovery of DNA. If you look at transport it was maybe the internal combustion engine and once those discoveries were made, once those changes happened nothing was ever the same again. I think ICT is our DNA, it's our internal combustion engine it is the trigger that can introduce a revolution in how we teach and in how we learn. (Morris, 2002)
}

Christine Steeples and I have discussed the persistence of the technological determinist approach in networked learning and its effect on policy elsewhere (Jones \& Steeples 2002). At this point I simply want to stress the idea that the debates about the information society (and more recently networked society) inform policy makers who in turn set the parameters for work in the field of networked learning. Advanced learning technology is introduced in relation to policy frameworks and funding decisions that are closely associated with claims that society is fundamentally transformed 
by the use of computer networks. Recently, Wolf (2002) has provided an illustration of how the view of a changing workforce, central to the idea of an information society, misinforms a major plank of government policy. The economic case for widening participation and the massification of higher education is closely related to the idea that services are replacing industries and that knowledge workers are replacing unskilled and manual work. In her conclusion, Wolf comments:

For the last quarter-century education policy has been driven consistently by preoccupation with growth and with workplace skills ... The results have been frequently disastrous.

(Wolf, 2002, p. 244)

It is not necessary to agree with Wolf's anti-government agenda to agree with this observation, which links failing policies with a particular view of the needs of an information society.

A second connection with the wider debate about network society is through the idea of virtual community. Rheingold's highly influential book The Virtual Community (1993) generalised from the WELL, a virtual community based in the San Fransisco Bay area in the mid-1980s. This book argued that the Internet opened up the possibility of a new form of community on-line, formed around shared values and interests. The accounts of community facilitated by computer networks, provided by Rheingold, have been aligned by others with social and situated views of learning and the idea of communities of practice in Computer Supported Collaborative (or Cooperative) Learning (CSCL). This claim about a technological basis for a new sociability formed a natural alliance with educational theories that placed an emphasis on communities of practice. Accounts of situated learning (e.g. Brown et al., 1989; Lave \& Wenger, 1991; Wenger, 1998) have had a particular influence. A community of practice has been defined by Wenger using three dimensions:

- what it is about-as a joint enterprise as it is understood and continually renegotiated by its members;

- how it functions-as a mutual engagement that binds members together into a social entity;

- what capability it has produced - the shared repertoire of communal resources members have developed over time, e.g. routines, sensibilities, artefacts and vocabulary.

This emphasis on collaboration and community stands in sharp contrast to the notion of networked individualism identified as a characteristic of networked society by Castells (1996, 2001).

The idea of communities of practice has recently come under critical review (Fox, 2002a; Hodgson \& Reynolds, 2002). Fox articulates a view of communities of practice as sub-units within wider actor-networks that include both animate and inanimate elements, described as actants. He argues that communities of practice rely on a romanticism derived from anthropological studies set outside of modern societies. He goes on to suggest that its application within modern bureaucratised organisations focuses on sub-cultures, non-canonical groups in the interstices of organisations. 
In summarising learning as peripheral participation in such communities of practice, Fox comments:

It is a community which is specialised around some specific practice or other, a single task, occupation, interest or profession. It may rely on a certain amount of formal education as a pre-requisite for joining (e.g. the US naval quartermasters often had to attend training school), but the real learning comes from the triadic communal relations between oldtimers, young journey-men and/or women and newcomers, i.e. real learning comes from the social relations between people with more knowledge and skill interacting with people with less knowledge and skill in the pursuit of a common practice. (Fox, 2002a, p. 111)

As an alternative to communities of practice Fox suggests actor-network theory (2002a, 2002b). In his view communities of practice may be seen as a special case in terms of actor networks as they have specific practices within them such as mimicry, demonstrating and working together. Beyond a certain scale Fox argues that a community of practice becomes an imagined community in which the actor-networks link and connect multiple communities of practice. The view Fox outlines is one that has a strong resonance with the observations by Castells in relation to networked individualism and community in networked society. Together they imply that communities and communities of practice are not the necessary or inevitable outcomes of networked society or networked technology; rather, they are special cases of more general network phenomena that rely on a particular form of individualisation.

Hodgson and Reynolds' critique of community focuses on power and democracy. They argue that networked learning offers a promising medium for supporting participative approaches to learning and that participative and democratic values are facilitated because it allows for the emergence of 'splinter' groups based on differences or differences of interests. They claim that traditional approaches tend to reflect notions of collaboration that discourage recognition of differences and that practices in networked learning still conform to that approach. In practical terms Trehan and Reynolds (2002) have noted that within peer assessed groups aspects of power relations, associated with wider social networks in education, impinge on the practices of a learning community intended to foster a cooperative and collaborative style of working. The comments of Hodgson, Reynolds and Trehan touch on some central questions in relation to networks and communities when they are applied to educational settings. Network metaphors can be used in such a way that power relations become diminished or invisible. The different access to resources held by actors in the network can be ignored by a focus on connections between nodes rather than on which nodes act as attractors in the flows across the network. In education the gloss of the 'guide on the side' has often ignored the power of the tutor in setting assessment tasks and in grading those assessments (Jones, 2000). As Trehan and Reynolds make clear, these power relationships are also evident in the interactions of collaborative and peer assessment.

\section{Networked learning in the network society}

The claim of this paper is that the use of the network metaphor can link the different aspects of research into the use of advanced learning technologies based on computer 
networks. In this section I want to draw attention to the connections at various levels and how the network metaphor might be applied. The aspects I will cover are not exhaustive but are intended to give a flavour of the range of issues to which this metaphor can be applied.

\section{Policy and politics}

Higher education is currently suffering a policy overload in the UK. The government White Paper issued in the spring of 2003 may either be on its way to implementation or dead in the water by the time this article appears in print. The entire process of consultation and negotiation of this policy will illustrate a powerful application of network theory in terms of government and governance. The idea of policy networks has developed in relation to a broad change in the relationship of government to society. The notion of governance has been used to separate out government action and actions that may include government and its agencies but which incorporate a network of bodies, some within and some outwith the boundaries of government itself. Governance in this sense refers to the management of 'self-organising, interorganisational networks with the following characteristics' (Rhodes, 1997):

1. interdependence between organisations;

2. continuing interaction between network members;

3. game-like interactions, rooted in trust and regulated by rules; and

4. no sovereign authority, self-organising, with a limited state steer.

Politically, this structure is an organisational Third Way, standing between the hierarchy associated with the bureaucratic active state and the anarchy of the market (Rhodes, 1997).

There are potential concerns that this form of governance is not as loose as it might appear at first glance. In managerial terms the autonomy of teams, brought together either for specific projects or as self-managing units, is circumscribed. An early commentator on new public sector management described such arrangements as 'freedom within boundaries' (Hoggart, 1991). In other words, networks can concentrate as well as disperse power. Power can be exercised in the setting of the limits within which component parts can operate. At another level, governance can concentrate its efforts on performance, on products not process. Traditional management might be concerned with the way that work was conducted, with process issues. Networked forms of governance shift concerns to outputs and performance, to what is done, not how it was achieved. The education system has been at the sharp end of reforms based on this model.

The network metaphor can also help evaluate novel policy initiatives. The evaluation of the UK's Learning and Teaching Support Network (LTSN) pointed to the network nature of the organisation and how this structure affected policy that flowed through it and its influence on policy formation. The Subject Centres had a high degree of autonomy in their dealings with subject communities and this in turn had a strong influence on how they developed. The overall structure of the LTSN was of a 
managed network and policy was introduced into this system through the Executive who had a close eye on government policy and the funding councils. The flow of policy initiatives was negotiated through this complex system in which power relations were often expressed through financial constraints. The LTSN provided an interesting example of how networks can provide a unique responsiveness to diverse interests and retain a degree of structure and control that makes them of interest to policy makers.

The LTSN is a policy initiative that relies upon remaining close to its constituency. To be effective that strand of the initiative is critical. Yet that requirement sets up a tension with the natural desire of the funding bodies and beyond them the government, to make such initiatives responsible for carrying through major items on the policy agenda (Jones, 2002).

Network metaphors are also useful in relation to new and developing forms of management. A Dutch school of political studies has moved from using network analysis to describe government to setting out some basic guidance on how networks can be managed (Kickert et al., 1997). This type of analysis may be especially appropriate in higher education, which has multiple centres of power and influence. Kickert et al. comment that "management in networks is about creating strategic consensus for joint action within a given setting" (p. 167).

Finding a common purpose for higher education is one of the great challenges in the midst of current social and technological changes, and for this an analysis of how managed networks operate is invaluable.

\section{Networked learning}

A first wave of writing about the use of computer networks in education took place in the late 1980s and early 1990s with the emergence of such canonical texts as Mindweave, The 'virtual classroom' and Online education (Mason \& Kaye, 1989; Hiltz, 1994; Harasim, 1990). The focus of these approaches was largely textual, emphasising the interactive nature of the technology and exploring how these could be used for distance education in particular. Mason (1994, p. 25) commented that:

\footnotetext{
No concept so characterises educational thinking in the 1990s as does interactivity... So embedded in the spirit of the age is it that there is relatively little questioning of its value, much less evaluation of its effects.
}

Interactivity altered its focus during this period from interacting with computers to interacting through computers (Crook, 1994). In 1996, Koschmann tried to periodise the developments in the context of research programmes (Koschmann, 1996), identifying an 'emerging paradigm' that he called CSCL. This emerging set of research questions was contrasted with previous outlooks, Computer Assisted Instruction, Intelligent Tutoring Systems and the 'Logo-as-Latin' paradigm associated with Papert's seminal text Mindstorms. Koschmann related the research within the CSCL paradigm to socially oriented constructivist viewpoints such as the Soviet sociocultural theories and theories of situated cognition. Likening the paradigm shifts 
he identified to a gestalt change in view, he claimed that the new paradigm drew attention to the social and cultural context of education as the object for research. In interviews with UK academics using networked learning, the paradigm identified by Koschmann has been found to provide a high level philosophy informing the thinking of practitioners in UK higher education (Jones et al., 2000; Jones \& Asensio, 2002).

In 2001 Koschmann returned to this theme and examined the emergent paradigm of CSCL in more detail:

CSCL research has the advantage of studying learning in settings in which learning is observably and accountably embedded in collaborative activity. Our concern, therefore, is with the unfolding process of meaning-making within these settings, not so-called 'learning outcomes'. It is in this way that CSCL research represents a distinctive paradigm within IT. By this standard, a study that attempted to explicate how learners jointly accomplished some form of new learning would be a case of CSCL research, even if they were working in a setting that did not involve technological augmentation. On the other hand, a study that measured the effects of introducing some sort of CSCL application on learning (defined in traditional ways) would not.

I find this definition of the field unsatisfactory precisely because it fails to relate the research area to the particular features or affordances of the technology. I would suggest that the technological change surrounding the Web, only in its infancy in 1996, has been the spur to generating another set of research questions in an area that I would describe as networked learning.

The Centre for Studies of Advanced Learning Technology (CSALT) group at Lancaster University and I have been associated with the following definition of networked learning:

Networked learning is learning in which information and communication technology (C\&IT) is used to promote connections: between one learner and other learners, between learners and tutors; between a learning community and its learning resources.

This definition of networked learning is, like CSCL, related to social theories of learning. It develops beyond CSCL in moving away from defining the new paradigm simply in terms of the local processes of social learning. Networked learning remains concerned with social process but it sets itself the task of understanding the links between different nodes, the learners, the tutors and the resources that make up a networked learning setting. The growth of the Web and the drive to digitise and make accessible a range of reified 'learning objects' has made the research focus on social process, understood as group collaboration, too narrow. It is important now to understand the relationship of individuals and groups to artefacts as a sense making activity. The move from interaction with computers to interaction through computers has now moved on to interaction in relation to computer networks. The computer itself is no longer the centre of research attention; instead it is the network and network resources made available through the computer. Indeed if mobile and ubiquitous computing develop strongly, the device through which the network is available may well cease to be recognisable as a computer. Networked learning can take account of policy, organisational and whole institution issues that arise with the embedding of the new network technologies. Networked learning is still concerned with meaning 
making and the social process of learning but it is also concerned with the social and organisational dynamics within which those processes take place.

\section{Research into networked learning}

As networked learning develops it will be increasingly important to develop an understanding of how traditional research approaches might transfer to networked environments. In my own field of interests there has been a growing interest in 'virtual' or 'on-line' ethnography. Hine (2000) comments on some of the ways that the virtual is distinct from face to face settings, noting that networked technologies show "a high degree of interpretive flexibility" (p. 64). She argues that this flexibility derives from the way the technology is dependent upon different contexts and the way that the technology has to be "acquired, learnt, interpreted and incorporated into context" (p. 64). Hine's conclusion is that:

Virtual ethnography is adequate for the practical purpose of exploring the relations of mediated interaction, even if not quite the real thing in methodologically purist terms. (p. 65)

Wittel has also explored the move 'From Field to Net to Internet' and has suggested a move to an ethnography of networks (2000).

\footnotetext{
Networks are still strongly related to geographical space-like field. Unlike field, a network is an open structure, able to expand almost without limits and highly dynamic. And even more important: A network does not merely consist of a set of nodes but also a set of connections between nodes. As such, networks contain as much movement and flow as they contain residence and localities. An ethnography of networks would contain the examination of nodes of a net and the examination of the connections and flows (money, objects, people, ideas etc) between these nodes.[5]
}

His conclusion is similar to Hine's, recommending a reshaping of the concept of field site to one focused on flow and connectivity. By continuing to place an emphasis on the node within a network, Wittel's formulation has the benefit of retaining some aspects of the idea of location within the expansion of the concept to cover flow and connectivity.

\section{Conclusions}

I have argued that using the metaphor of networks can assist us to theorise the broad context in which learning and education take place in a society reliant on computer networks. I have not outlined a research programme associated with this view but there are within this article strong hints that such a research programme could and possibly should be elaborated. Networks provide a useful focus for analysing the patterns of growth and interaction in a wide range of fields. The use of the network metaphor in learning technology helps us to connect ourselves to that wider debate and to theorising about the fundamental nature of the network and patterns of activity associated with it. The use of the network metaphor also links our work in learning technology with that concerning the network society. This has direct connections to 
learning technology because it informs debates in higher education and training in terms of the type of workforce that awaits our current students and the type of skills they are likely to need.

The networked society debate directly relates to the ideas of virtual communities and communities of practice. Network theory suggests that the strong notions of community within these theoretical approaches might ignore the importance of the 'strength of weak links'. Networks can be structured in ways that combine both the benefits of random and organised patterns. The educational focus on strong links and community may have made less visible those necessary but weak connections that make the network idea so powerful. The idea of online communities also tends to separate out and privilege the virtual against the real. The ideas of online and offline communities need to merge in the activity of real people who are both simultaneously on and offline when they are engaged with computer networks.

In relating networked learning to the networked society this paper has identified three areas that may be open to investigation using network analysis. Policy, politics and management is one area in which network analysis is already well developed in ways that may be of direct use for researchers in learning technology. This is also an area in which the idea of networks can help social practice theories of social and situated learning connect themselves to the policy debate. The idea of clusters and hubs in hierarchical networks may allow us to develop a rich picture of just how it is that communities of practice relate to the wider policy networks in education. In terms of the current dominant paradigms influencing learning technologists, the network metaphor assists in shifting the emphasis towards the reifications deployed in networks alongside a focus on meaning-making. Finally the paper raises the question of research methods. It raises the possibility that researchers may need to adjust and amplify their methods to take advantage of new possibilities and to translate classic research methods into the network setting.

\section{Acknowledgements}

This paper is based on a research paper presented at $A L T-C 2003$ and published in the conference's research proceedings.

\section{References}

Barabasi, A-L. (2002) Linked: the new science of networks (Cambridge, MA, Perseus Publishing).

Barabasi, A-L., Dezso, Z., Ravasz, E., Yook, S-H. \& Oltvai, Z. (2002) Scale-free and hierarchical structures in complex networks. Available online: http://www.nd.edu/ networks/PDF/Proceeding\%20Sitges2004.pdf (accessed 25 November 2003).

Barnett, R. (2000) Realizing the university in an age of supercomplexity (Buckingham, SRHE/Open University Press).

Bell, D. (1974) The coming of post-industrial society: a venture in social forecasting (Hamondsworth, Penguin).

Brown, J., Collins, A. \& Duguid, P. (1989) Situated cognition and the culture of learning, Educational Researcher, 18(1), 32-42. 
Buchanan, M. (2002) Nexus: small worlds and the groundbreaking science of networks (London, W.W. Norton \& Co).

Castells, M. (1996) The information age: economy, society and culture. Volume 1: The rise of the network society (Oxford, Blackwell).

Castells, M. (2001) The Internet galaxy: reflections on the Internet, business, and society (Oxford, Oxford University Press).

Crook, C. (1994) Computers and the collaborative experience of learning (London, Routledge).

Fox, S. (2002a) Networks and communities: an actor-network critique of ideas on community and implications for networked learning, in: S. Banks, P. Goodyear, V. Hodgson \& D. McConnell (Eds) Networked learning 2002: a research based conference on e-learning in higher education and lifelong learning (Sheffield, University of Sheffield), 110-118.

Fox, S. (2002b) Studying networked learning: some implications from socially situated learning theory and actor-network theory, in: C. Steeples \& C. Jones (Eds) Networked learning: issues and perspectives (London, Springer).

Harasim, L. (Ed.). (1990) Online education; perspectives on a new environment (New York, Praeger).

Hiltz, S. (1994) The virtual classroom: learning without limits via computer networks (Norwood, NJ, Ablex).

Hine, C. (2000). Virtual ethnography (London, Sage).

Hodgson, V. \& Reynolds, M. (2002) Networked learning and ideas of community, in: S. Banks, P. Goodyear, V. Hodgson \& D. McConnell (Eds) Networked learning 2002: a research-based conference on e-learning in higher education and lifelong learning (Sheffield, University of Sheffield), 119-127.

Hoggart, P. (1991) A new management in the public sector? Policy and Politics 19(4), 243-256.

Jones, C. \& Steeples, C. (2002) Perspectives and issues in networked learning, in: C. Steeples \& C. Jones (Eds.) Networked learning: perspectives and issues (London, Springer).

Jones, C. (2000) From the sage on the stage to what exactly? Description and the place of the moderator in cooperative and collaborative learning, in: D. Squires, G. Jacobs \& G. Conole (Eds) The changing face of learning technology—selected papers from ALT-f (Cardiff, University of Wales Press).

Jones, C. (2002) Is there a policy for networked learning? In: S. Banks, P. Goodyear, V. Hodgson \& D. McConnell (Eds) Networked learning 2002: a research-based conference on e-learning in higher education and lifelong learning (Sheffield, University of Sheffield), 175-182.

Jones, C. \& Asensio, M. (2002) Designs for networked learning in higher education: a phenomenographic investigation of practitioners' accounts of design, in: C. Steeples \& C. Jones (Eds) Networked learning: perspectives and issues (London, Springer).

Jones, C., Asensio, M. \& Goodyear, P. (2000) Networked learning in higher education: practitioners' perspectives, $A L T-\mathcal{F}, 8(2), 18-28$.

Kickert, W., Klijn, E-H. \& Koppenjan, J. (1997) Managing complex networks (London, Sage).

Koschmann, T. (2001) Revisiting the paradigms of instructional technology, in: G. Kennedy, M. Keppell, C. McNaught \& T. Petrovic (Eds) Meeting at the Crossroads: Proceedings of the 18th Annual Conference of the Australian Society for Computers in Learning in Tertiary Education (Melbourne, The University of Melbourne), 15-22. Available online: http:// www.medfac.unimelb.edu.au/ascilite2001/pdf/papers/koschmannt.pdf (accessed 28 February 2003).

Koschmann, T. (Ed.) (1996) CSCL: theory and practice of an emerging paradigm (Mahwah, NJ, Lawrence Erlbaum Associates).

Lave, J. \& Wenger, E. (1991) Situated learning: legitimate peripheral participation (Cambridge, Cambridge University Press).

Law, J. (Draft) Networks, relations, cyborgs: on the social study of technology, Centre for Science Studies and the Department of Sociology, Lancaster University. Available online: http:// www.comp.lancs.ac.uk/sociology/soc042jl.html (accessed 24 February 2003). 
Lyon, D. (1995) The roots of the information society idea, in: N. Heap, R. Thomas, G. Einon, R. \& H. Mackay (Eds) Information technology and society: a reader (London, Sage).

Mason, R., Kaye, A. (Eds) (1989) Mindweave: communication, computers and distance education (Oxford, Pergamon).

Mason, R. (1994) Using communications media in open and flexible learning (London, Kogan Page).

Morris, E. (2002) Speech to BETT Conference Available online: http://www.dfes.gov.uk/speeches/ index-shtml (accessed 12 March 2004).

Rheingold, H. (1993) The virtual community: homesteading on the electronic frontier (Reading, MA, Addison-Wesley).

Rhodes, R. (1997) Understanding governance: policy networks, governance, reflexivity and accountability (Buckingham, Open University Press).

Toffler, A. (1980) The third wave (London, Pan).

Trehan, K. \& Reynolds, M. (2002) Online collaborative assessment: power relations and 'critical learning', in: C. Steeples \& C. Jones (Eds) Networked learning: perspectives and issues (London, Springer).

Watts, D. \& Strogatz, S. (1998) Collective dynamics of 'small world' networks, Nature, 393, 440-442.

Wenger, E. (1998) Communities of practice: learning, meaning, and identity (Cambridge, Cambridge University Press).

Wittel, (2000) Ethnography on the move: from field to net to Internet [23 paragraphs]. Forum Qualitative Socialforschung/Forum: Qualitative Research, 1(1). Available online: http://qualitative-research.net/fqs (accessed 12 March 2004)1

Wolf, A. (2002) Does education matter? Myths about education and economic growth (London, Penguin Books). 